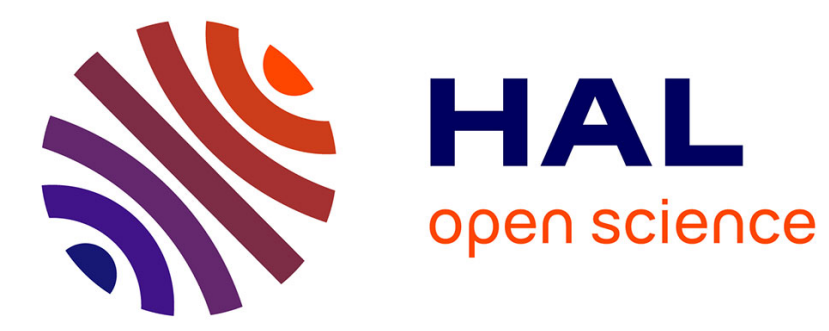

\title{
Semantic Technologies and Learning
}

Thanassis Tiropanis, Hugh C. Davis, Stefano A. Cerri

\section{To cite this version:}

Thanassis Tiropanis, Hugh C. Davis, Stefano A. Cerri. Semantic Technologies and Learning. Encyclopedia of the Sciences of Learning, Part 19, Springer, pp.3029-3032, 2012, 10.1007/978-1-4419-14286_1096. lirmm-00670658

\section{HAL Id: lirmm-00670658 https://hal-lirmm.ccsd.cnrs.fr/lirmm-00670658}

Submitted on 16 Feb 2012

HAL is a multi-disciplinary open access archive for the deposit and dissemination of scientific research documents, whether they are published or not. The documents may come from teaching and research institutions in France or abroad, or from public or private research centers.
L'archive ouverte pluridisciplinaire HAL, est destinée au dépôt et à la diffusion de documents scientifiques de niveau recherche, publiés ou non, émanant des établissements d'enseignement et de recherche français ou étrangers, des laboratoires publics ou privés. 


\section{Metadata of the chapter that will be visualized online}

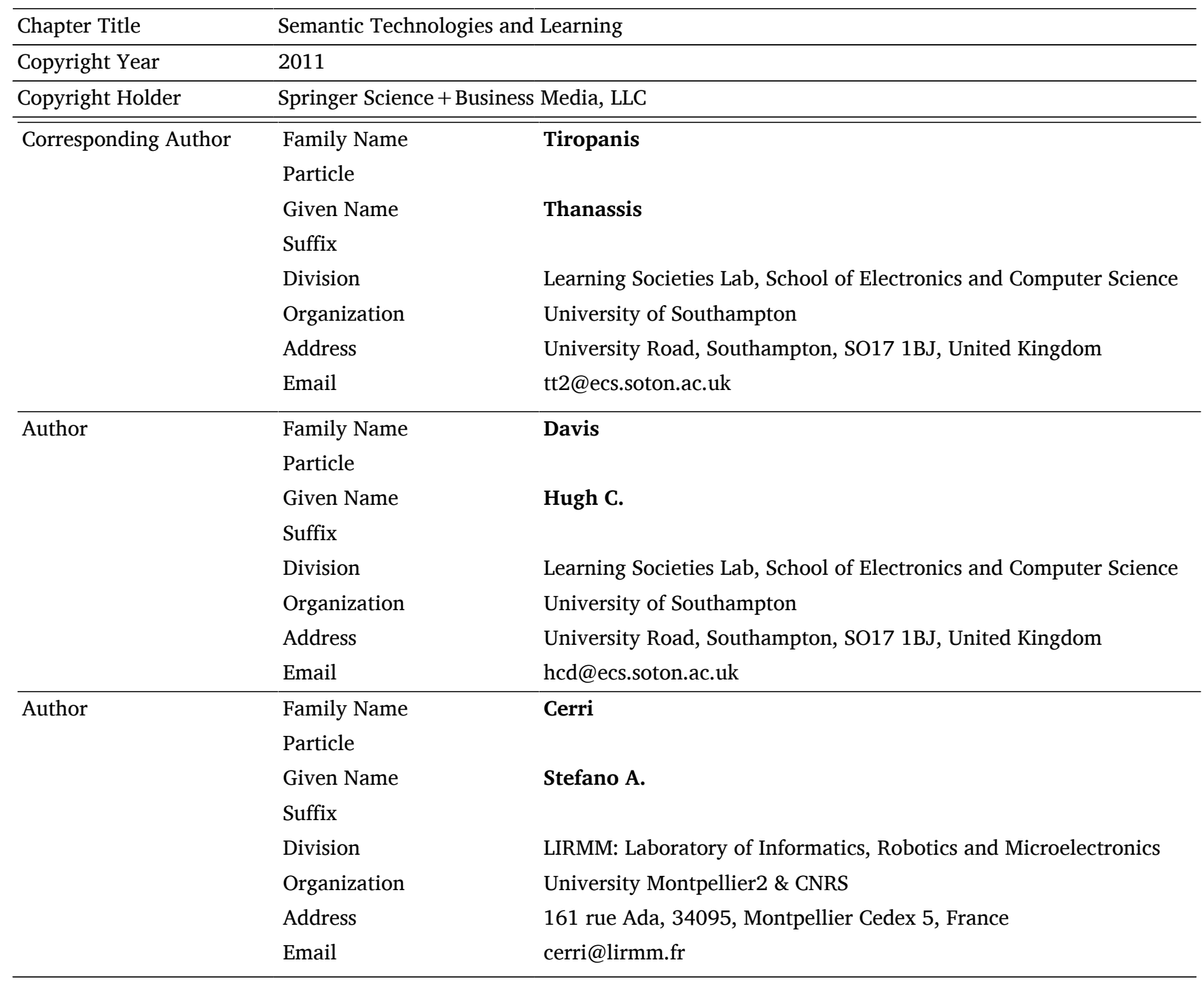




\section{Semantic Technologies and Learning}

Thanassis Tiropanis ${ }^{1}$, Hugh C. Davis ${ }^{1}$, Stefano A. Cerri ${ }^{2}$

${ }^{1}$ Learning Societies Lab, School of Electronics and Computer Science, University of Southampton, Southampton, United Kingdom

${ }^{2}$ LIRMM: Laboratory of Informatics, Robotics and Microelectronics, University Montpellier2 \& CNRS, Montpellier Cedex 5, France

\section{Synonyms}

Knowledge representation and reasoning and learning; Linked data and learning; Semantic web and learning

\section{Definition}

Semantic technologies provide for the expression of meaning of resources such as content, software, systems, people, and communities in machine processable formats with the help of ontologies. Ontologies provide the vocabulary for describing resources and their relationships (Gruber 1993; Musen 1992). Based on the meaning of resources, semantic technologies can draw conclusions and enable better resource discovery and matching.

In a learning context, the potential of semantic technologies translates to a number of affordances. The types of resources involved in formal or informal learning environments could include learners, teachers, software, services and content. Given the description (or annotation) of these resources with the help of ontologies, it is possible to support more efficient discovery of learning resources, sequencing of relevant learning material, adaptation of learning experiences to match learner profiles, formation of groups for teaching learning activities, collaborative construction of knowledge, recommendation of learning resources and activities, and assessment. A number of ontologies are developed in the learning domain in order to support these applications with the help of reasoning software.

\section{Theoretical Background}

Semantic technologies for learning draw from work in 39 Knowledge Representation and Reasoning and have been 40 significantly influenced by developments in the Semantic 41 Web community (Berners-Lee et al. 2001). The Semantic 42 Web vision has been considered "inevitable" and its 43 impact on education significant (Ohler 2008). 44

With the help of ontologies, semantic technologies can 45 support knowledge representation and reasoning. There 46 are a number of ontology languages to address the tradeoff 47 between how expressive an ontology language is and the 48 performance of reasoning based on resources annotated 49 with this ontology language. Resource descriptions in 50 more expressive ontology languages could potentially let 51 us perform advanced reasoning and draw more conclu- 52 sions about resources, at the cost, however, of increased 53 computation and potentially reduced performance. $\quad 54$

For example, some ontology languages let us use 55 transitive properties when describing how resources relate 56 to each other, which can provide for more powerful rea- 57 soning. Consider an ontology for the domain of language 58 education. We could identify concepts such as student and 59 class and relationships that express that a student attends 60 one class only or that a student is a classmate of another 61 student; one could also specify that the relationship "is 62 a classmate of "its transitive (i.e., if $\mathrm{A}$ is a classmate of 63 $\mathrm{B}$ and $\mathrm{B}$ is a classmate of $\mathrm{C}$ then $\mathrm{A}$ is a classmate of $\mathrm{C}$ ). 64 Given this ontology, one can annotate (mark up) specific 65 resources as instances of ontology concepts. For example, 66 one could mark up each of "Alice," "Bob," and "Eve" as 67 instances of a student and "French" as an instance of a class; 68 one could also state that "Alice" is a classmate of "Bob,"that 69 "Bob" is a classmate of "Eve," and that "Eve" attends 70 "French." Given this annotation and the ontology, it is 71 possible to draw conclusions with the help of software; in 72 this example, software could infer that "Alice" attends 73 "French" and that "Alice" is a classmate of "Eve" even if 74 this information is not explicitly stated in the annotation. 75

The power of knowledge representation and reasoning 76 bears significant promise for learning. In addition, the 77 well-formed description of resources with the use of light- 78 weight or more expressive ontologies bears potential for 79 interoperability and data integration. This has led to 80 
research on the use of semantic technologies in a number of areas related to learning.

\section{Semantic Technology Affordances}

The promise of semantic technologies in learning has been identified as an important aspect of Technology Enhanced Learning (TEL) in both formal and informal learning settings. The ability of semantic technologies to match people, content, and communities that are involved in learning processes is central in all these areas.

Matching learners to learning resources has led to work on the integration of semantic technologies Learning Management Systems (LMS), Learning Content Management Systems (LCMS), or Virtual Learning Environments (VLE). The role of semantic technologies in these domains is on discovering, sequencing, or adapting learning material based on the learner profile and learning outcomes. Semantic technologies have been considered in the context of collaborative building of knowledge and learning material by means of collaborative ontology building, topic maps and semantic wikis. Collaborative ontology building tools have also been developed to that end.

The use of semantic technologies to match learners to other learners or teachers has been considered in groupformation systems in formal learning and informal learning settings. In vocational training, semantic technologies have been proposed to form groups of learners with similar or supplementary competencies. In informal learning, successfully matching learners based on their profiles and their learning objectives using semantic technologies has been pursued.

Another significant advantage of semantic technologies is in matching content and people involved in learning processes on a large scale: a larger pool of people and content increases the chances of accurate matching. In this respect, the semantic description of resources available in repositories of reference material has been used for advanced content discovery. Semantic applications to support critical thinking and argumentation by enabling the discovery of material in support or against a certain argument are also being explored. At the same time, aggregating and processing information about people and their activity using semantic technologies has led to work on expert matching tools and query answering. Ontologies for describing relationships among people such as the Friend-of-a-Friend (FOAF) ontology enable additional tools on discovering people and supporting informal learning processes.

Semantic technologies can support a number of processes in formal education institutions such as assessment. In the environment of assessment semantic technologies can help in preparing appropriate assessment material 131 that matches certain assessment criteria or in the analysis 132 of text that is submitted as part of assessment; there are 133 examples of use of semantic technologies for both sum- 134 mative and formative assessment.

Semantic technologies can also support well-formed 136 description of resources in a formal education environ- 137 ment and address interoperability and data integration 138 requirements inside and across education institutions. In 139 the context of formal education, the data interoperability 140 and integration affordances of semantic technologies can 141 support efficient systems for curriculum design, develop- 142 ment of learning material, and collaboration among the 143 people involved in teaching and learning activities. 144

\section{Building Semantic Technologies 145}

Different approaches can be followed when it comes to 146 developing semantic technologies in a specific domain. 147 One can consider a top-down approach where the use of 148 an ontology or a set of ontologies are agreed first before 149 the annotation of resources and the deployment of appli- 150 cations. An alternative approach gives priority to exposing 151 data sources using lightweight vocabularies first, in order 152 to enable data interoperability and integration before 153 considering more complex ontologies in the context of 154 specific applications. The latter view is central in the 155 linked data movement (http://linkeddata.org/), which 156 proposes practices for exposing and connecting structured 157 data on the Web (Bizer et al. 2009). The Linked Data 158 movement supports the exposure of data sources in light- 159 weight vocabularies such as RDF (http://www.w3.org/ 160 $\mathrm{RDF} /$ ) in order to allow for the emergence of intelligent 161 applications that will make use of the exposed data. 162

The value of semantic technologies and linked data in 163 terms of well-formed description of resources, data 164 interoperability, and data integration in the UK higher 165 education sector has been highlighted in a number of 166 reports (Tiropanis et al. 2009). The types of semantic 167 technologies that are related to learning and which can 168 benefit from the linked data approach include: 169

- Collaborative authoring and annotation tools 170

- Searching and matching tools based on linked data 171 resources (e.g., expert finders) 172

- Repositories and VLEs that import or export their data 173 in linked data formats to support learning resource 174 discovery

In parallel to the Semantic Web vision, there are pro- 176 posals for a Pragmatic Web (http://www.pragmaticweb. 177 info), in which the description of the meaning of resources 178 is based not just on the semantic constructs and their 179 
relations as defined in ontologies, but also on the context in which resources are found and used. This contextual information could provide for more accurate mechanisms for learning resource discovery and use.

\section{Important Scientific Research and Open Questions}

Research on semantic technologies in learning has been developing in several directions. A non-exhaustive list of such directions and open research questions includes:

- Collaborative knowledge representation and maintenance in learning environments

- Supporting personal and group knowledge construction with semantic technologies

- Establishing the underpinning pedagogy of semantic applications or introducing pedagogy in semantic applications

- Knowledge extraction on resources related to learning

- Transition from taxonomies and hierarchies to more expressive ontologies for learning

- Semantic applications for critical thinking and argumentation

- Exploring the potential of semantic technologies for exploratory learning and problem-based learning

- Investigating the potential of sharing and combining linked data inside or across educational institutions

- Semantic technologies to capture and enhance informal learning processes

There are of systems that can support personal or collaborative knowledge construction, which are often Wiki-based or Topic-map based. In many cases, the constructed knowledge is not available in machine processable formats or formats that are appropriate for integration with other relevant applications. This opens siginificant questions on the feasibility, scalability, and efficiency of semantic technology based approaches to learning resource authoring and to data interoperability and integration for learning systems. In addition, the 216 potential of semantic technologies to support pedagogy 217 in technology-enhanced learning requires further 218 research. Semantic applications seem promising in 219 supporting critical thinking and argumentation given the 220 availability of relevant resources and applications. 221 Applications that combine resources described using 222 lightweight vocabularies on a large scale, across educa- 223 tional institutions and organizations, could potentially 224 support novel processes for formal, informal, exploratory, 225 and problem-based learning.

\section{Cross-References}

- Collaborative Knowledge Building

- Knowledge Acquisition: Constructing Meaning from 229

Multiple Information Sources

- Knowledge Organization

- Knowledge Representation

- Ontology and Semantic Web

- Ontology Development and Learning

- Ontology of Learning Objects Repository for

Knowledge Sharing

- Semantic Networks to Support Learning

\section{References}

Berners-Lee, T., Hendler, J., \& Lassila, O. (2001). The Semantic web. 239 Scientific American, 284(5), 29-37.

Bizer, C., Heath, T., \& Berners-Lee, T. (2009). Linked data-the story so far. 241 International Journal on Semantic Web and Information Systems, 5(3), 242 $1-22$.

Gruber, T. R. (1993). A translation approach to portable ontology spec- 244 ification. Knowledge Acquisition, 5, 199-220.

Musen, M. A. (1992). Dimensions of knowledge sharing and reuse. 246 Computers and Biomedical Research, 25, 435-467. 247

Ohler, J. (2008) The Semantic web in education. Educause Q, 31(4). 248 http://net.educause.edu/ir/library/pdf/EQM0840.pdf. 249

Tiropanis, T., Davis, H., Millard, D., Weal, M., White, S. and Wills, G. 250 Au1 (2009). Semantic technologies in learning and teaching (SemTech) - 251 JISC Report. 
Author Query Form

Encyclopedia of the Sciences of Learning

Chapter No: 1096

\begin{tabular}{|l|l|l|}
\hline Query Refs. & Details Required & Author's response \\
\hline AU1 & $\begin{array}{l}\text { Please provide missing details for the reference } \\
\text { "Tiropanis et al. (2009)". }\end{array}$ & Publisher: Joint Information Systems Comnittee (JISC), \\
\hline
\end{tabular}

URL: http://www.jisc.ac.uk/media/documents/projects/semtechreport.pdf.

Also: proposing the use of quotes in page 1, column 2, line 62 as indicated in 